\title{
¿Ha desaparecido Dios de nuestra literatura?
}

María Caballero

Catedrática de Literatura Hispanoamericana

Universidad de Sevilla

\begin{abstract}
Resumen: Este trabajo aborda la relación entre el Dios cristiano y la literatura occidental. Lo hace entresacando algunos momentos de especial relevancia a lo largo de la historia. Y termina planteándose la vigencia del tema en nuestro mundo actual.
\end{abstract}

Palabras claves: Dios, cristianismo, literatura.

\begin{abstract}
The paper is about the relationship between Christian God and occidental literature, Its autor focuses on some relevant moments in occidental story, and she ends by analyzing the validity of the topic in our days.
\end{abstract}

Keywords: God, Christianism, literature.

Literatura del siglo XX y cristianismo ${ }^{1}$ fue el título de un libro emblemático... Un libro codiciado por quienes recién llegados a la universidad no podían ni soñar adquirir, pero de esos que permanecen en el imaginario. Un libro en seis volúmenes (que después se ampliaron) escrito en francés (1953) por Charles Moeller (1912), y cuya traducción (1963) le supuso un premio del Gobierno belga al eminente catedrático de griego Valentín García Yebra. Allí se desplegaba ante los ojos del lector todo un mundo de apasionantes preguntas, problemas, dudas... en torno a los grandes nombres contemporáneos: "El silencio de Dios", vol. I (Camus, Gide, Huxley, Simone Weil, Graham Greene,

1 Cf. Charles Moeller, Literatura del siglo XX y cristianismo, Madrid, Gredos, 1970-75 (edición original 1953).

Fecha de recepción: 1 de mayo de 2019

Fecha de aceptación y versión final: 1 de junio de 2019

https://doi.org/10.46543/ISID.1928.1007 I ISSN: 1131-7027 I ISSN-e: 2660-7743 
Julien Green, Bernanos); "La fe en Jesucristo”, vol. II (Sartre, H. James...); "La esperanza humana”, vol. III (Malraux, Kafka, Maulner, F. Sagan....; La esperanza en Dios nuestro Padre", vol. IV (Ana Frank, Unamuno, G. Marcel, Péguy...); "Amores humanos", vol.V (Bertolt Brecht, Saint-Exupéry, Simone de Beauvoir, Valery, Sant-John Perse...); "Exilio y regreso", vol.VI (Marguerite Duras, Ingmar Bergman, Valery Larbaud, F. Mauriac, Sigrid Unset, Gertrud le Fort), etc.

Habría que preguntar si alguien sería hoy capaz de semejante proeza, valorar en su calado ontológico además de literario la escritura de tantos y tan grandes autores, incluidos varios premios Nobel. Más inquietante sería plantearse si en los últimos setenta $u$ ochenta años los seres humanos han escrito algo semejante o, incluso, si han sido capaces de vivir su existencia con tanta hondura. Respecto a lo primero, podría decirse con Octavio Paz que"el hombre es hombre gracias al lenguaje, gracias a la metáfora original que le hizo ser otro y lo separó del mundo natural" ${ }^{2}$ El poeta, que todavía en el romanticismo se consideraba puente hacia la divinidad, que era el traductor hacia el resto de los mortales de ese libro de Dios plasmado en la naturaleza, se rebela ¡nuevo Lucifer! y declara concluida su labor de copista. La crisis finisecular del XIX (modernismos, decadentismos...) introduce la duda metafísica, tan bien plasmada en el poema Lo fatal, de Cantos de vida y esperanza (Rubén Darío, pecador y arrepentido, nuevo Lope deVega que, por cierto, tiene a Dios muy presente en su poesía):

“Dichoso aquel que es apenas sensitivo,
Y más la piedra dura porque ésa ya no siente,
Pues no hay dolor más grande que el dolor de ser vivo,
Ni mayor pesadumbre que la vida consciente.

Ser, y no saber nada, y ser sin rumbo cierto, Y el temor de haber sido y un futuro terror... Y el espanto seguro de estar mañana muerto, Y sufrir por la vida y por la sombra y por

lo que no conocemos y apenas sospechamos, Y la carne que tienta con sus frescos racimos, Y la tumba que aguarda con sus fúnebres ramos, ¡Y no saber adónde vamos, ni de dónde venimos!". ${ }^{3}$

El tono es nostálgico, de despedida de seguridades y valores que han sostenido durante siglos al ser humano. Estamos ante las consecuencias de la consabida proclamación de la muerte de Dios por parte de Nietzsche y algunos otros. Y de cuestiones históricas más complejas, bien conocidas en las que no

2 Octavio Paz, Los hijos del limo. Del Romanticismo a la Vanguardia, Barcelona, Seix Barral, 1993, 34.

3 Rubén Darío, “Lo fatal”, Cantos de vida y esperanza, Madrid, Cátedra, 1995, 466. 
merece la pena entrar. A partir de la década de 1910 y la tragedia de la primera guerra mundial, un nuevo siglo mucho más desacralizado se abre paso. En él triunfan las vanguardias artísticas: la poesía es el nuevo sagrado, sustituye a la religión — ha dicho el poeta, ensayista y Nobel mexicano Octavio Paz-.

Recogiendo el título del trabajo y ante la pregunta, ¿qué aportó el cristianismo a la literatura occidental? surgen múltiples respuestas: la Biblia ${ }^{4}$, cantera literaria para todos los tiempos; la mística ${ }^{5}$, puente indestructible entre Dios y los hombres; la literatura de los conversos, desde Agustín de Hipona hasta la princesa Borghese, pasando por Claudel, Frossard, García Morente, Hahn, etc.; la literatura apologética que dio grandes ensayos y también novelas, a veces obra de conversos: Fabiola, del cardenal Wiseman; Apologia pro vita sua (ensayo) y Perder y ganar (novela autobiográfica), doble testimonio de la conversión de Newman, que además nos ha legado una amplia colección de sermones; los múltiples y excelentes relatos de Lewis, Chesterton, E. Waugh, etc. Pero el cristianismo aportó mucho más, como es patente al estudiar el tema de Dios en la novela del siglo xx: S. Undset, H. Haase, V. Horia, Mauriac... con un importante apartado sobre el mal, ese escollo de todos los tiempos que bordan Dostoiewski o Hanah Arent. Y cuando parece que hoy Dios ya no interesa a los escritores, encontramos en la novela postmoderna, una cierta nostalgia del Dios perdido, por ejemplo, en La carretera ${ }^{6}$, de McCarthy. Sucede algo semejante con la poesía religiosa, veta escondida que, como nuevo Guadiana, aflora en excelentes escritores: Gerardo Diego, J. Ma Pemán, E. de Champourcín, Dámaso Alonso... y en generaciones mucho más cercanas a nosotros: Miguel d’Ors, J. J. Cabanillas, Carmelo Guillén... Como muestra un botón: la antología Dios en la poesía actual (2018) $)^{7}$, recientemente editada por los dos poetas que acabo de citar, en voluntaria continuidad y carrera de relevos con la que en 1970 preparara para la BAC Ernestina de Champourcín ${ }^{8}$, poeta del 27 y republicana exilada en México.

Habría mucho que hablar, porque si el monumental libro de Charles Moeller es una mina inagotable que permite a los profesores cubrir varios cursos académicos con la presencia o ausencia divina en los textos, el tema que se estudia lo rebasa y va más allá. Unas simples calas lo demostrarán, abrirán horizontes en busca de respuestas a las grandes inquietudes. Aquellas que como seres únicos e irrepetibles debemos resolver uno a uno sabiendo, eso sí, que nos unen al resto de la humanidad. Algo que el poeta argentino Borges supo plasmar desde sus veinte años: en el trasfondo de su poesía, en sus ensayos, en sus relatos están las preguntas por el sentido del hombre, del mundo, de Dios a

4 Cf. Gregorio del Olmo (coord.), La Biblia en la literatura española, Madrid, Trotta, 2008.

5 Cf. Luce López-BARALt, El sol a media noche. La experiencia mística: tradición y actualidad, Madrid, Trotta, 1996.

6 Cf. Cormac McCArThy, La carretera, Barcelona, De Bolsillo, 2007.

7 Cf. José Julio Cabanillas - Carmelo Guillén (eds.), Dios en la poesía actual (colección Adonais), Madrid, Rialp, 2018.

8 Cf. Ernestina de Champourcín, Dios en la poesía actual, Madrid, BAC, 1970. 
pesar de su proclamado agnosticismo."Borges se cree autorizado a llamar a juicio al Dios cristiano para imputarle los males del mundo y condenarle, llegado el caso, a la pena de inexistencia" — dice Arana en El centro del laberinto... un libro excelente sobre las claves filosóficas del argentino ${ }^{9}$ —. Si a algún gremio se afilia el escritor argentino es al de quienes de antemano rechazan lo sobrenatural:

"Borges, usando un vocablo que le gusta ha fatigado la historia de las religiones, los catálogos de sectas y herejías, las antologías filosóficas y las recopilaciones de mitos, sin encontrar una creencia en la que pueda reconocerse, un Dios en el que su espíritu fuera capaz de reposar". ${ }^{10}$

A pesar de lo cual dice en su poema“'Xto en la cruz":"no veo / y seguiré buscándolo hasta el día / último de mis pasos por la tierra" . ${ }^{11} Y$ así fue: Dios presente hasta en su lecho de muerte — según testimonia su viuda, María Kodama — en una anécdota que contó hace años en Viena: pidió un pastor protestante y un cura católico y con ellos se encerró para seguir buscando... Impresionante.

\section{EL CRISTIANISMO Y LA CIVILIZACIÓN OCCIDENTAL}

Darío y Borges, dos clásicos de la literatura hispanoamericana que en absoluto se desligan del Dios cristiano. Y es que ¿cómo podría entender nuestra civilización europea sus claves culturales (arte, literatura... incluso cine) si prescinde de su historia religiosa? Pueden rastrearse figuras e historias bíblicas en escritores de todos los tiempos: Dante, Baudelaire, Goethe, Milton, Lord Byron... pero también el teatro misionero, los autos sacramentales y la poesía de los Siglos de Oro (Calderón y Lope...). Entre nosotros corren libros acerca de Lo que Europa debe al cristianismo ${ }^{12}$, o Cómo la Iglesia construyó la civilización occidental $^{13}$, que no hacen sino recordarnos a nivel de divulgación la labor de los monjes en los monasterios, la construcción de las universidades, la preservación de la cultura grecorromana:

"Según la experiencia histórica, hasta ahora, la religión ha sido la clave de todas las culturas y civilizaciones conocidas (...). Y muchas de las ideas que configuran Europa son de origen cristiano o han sido reelaboradas, cernidas, tamizadas o adaptadas por el cristianismo". ${ }^{14}$

9 Juan Arana, El centro del laberinto. Los motivos filosóficos en la obra de Borges, Pamplona, EUNSA, 1994, 83.

10 ARANa, El centro del laberinto, 99.

11 Jorge Luis Borges, Obras Completas I-II, Buenos Aires, Emecé, 1989.

12 Cf. Dalmacio Negro, Lo que Europa debe al cristianismo Madrid, Unión editorial, 2004.

13 Cf. Th. E. Jr. Woods, Cómo la Iglesia construyó la civilización occidental, Prólogo del Cardenal Antonio Cañizares, Madrid, Ciudadela, 2010.

14 Negro, Lo que Europa debe, 2. 
Que, no se olvide, es una religión y no debe confundirse de entrada con "cultura o civilización", aunque las impregne.

Una pregunta obligada, entonces, que desencadena en cascada un inevitable torbellino: ¿Tienen vigencia hoy la Biblia o los místicos? ¿Se sigue convirtiendo la gente? ¿En las últimas décadas, puede hablarse de una literatura en busca de Dios? Vamos por partes.

Comencemos con un par de ejemplos del siglo xx hispanoamericano (existen amplias monografías con uno y mil títulos en débito a la Biblia): Pedro Páramo $(1955)^{15}$, del mexicano Juan Rulfo parece un recorrido por infierno y purgatorio en busca del padre perdido (¿tal vez ese dios desconocido por el protagonista?), tras la culpa que condensa una doble tradición: la occidental bíblica y la azteca, según la cual Quetzalcoatl, uno de sus principales dioses, se embriaga y comete incesto con su hermana. Avergonzado huirá y no podrá regresar hasta la necesaria reparación. Una muestra del existencialismo francés que llega a México en esta etapa. En cuanto a Cien años de soledad (1967, la emblemática novela del colombiano Gabriel García Márquez), ${ }^{16}$ está diseñada con una estructura bíblica: se abre con un nuevo Génesis: el destierro de una pareja de recién casados y la fundación de Macondo (un reino, un pueblo, una comunidad... símbolo de nuestro mundo). Allí vivirán los protagonistas hasta que un viento huracanado los destruya por completo, en lo que es un imaginado Apocalipsis. Las profecías se han cumplido, la historia se ha cerrado; una historia que incluye parodias de referentes sagrados: Remedios la bella es elevada a los cielos como una nueva Virgen María...

¿Puede olvidar nuestra sociedad la belleza del Cantar de los Cantares ${ }^{17}$, expresión del amor erótico de un Dios que busca con pasión a las criaturas? Las estrofas del Cántico espiritual, de san Juan de la Cruz (1542-1591), escrito en la prisión hacia 1577, no dejan lugar a dudas de la herencia del Cantar de los Cantares:

¿Adónde te escondiste,

Amado, y me dejaste con gemido?

Como el ciervo huiste,

Habiéndome herido;

Salí tras ti clamando y eras ido (...)

Entrádose ha la esposa

En el ameno huerto deseado

Y a su sabor reposa

El cuello reclinado

Sobre los dulces brazos del Amado. ${ }^{18}$

15 Cf. Juan Rulfo, Pedro Páramo, Madrid, Cátedra, 1988.

16 Cf. Gabriel García Márquez, Cien años de soledad, Buenos Aires, Sudamericana, 1967.

17 Cf.Valentín NúNezz Rivera, Poesía y Biblia en el Siglo de Oro. Estudios sobre los Salmos y el Cantar de los Cantares. Madrid, Iberoamerican/Vervuert, 2010.

18 Juan de la CRUz, Obras completas, edición P. José Vicente de la Eucaristía, Madrid, Editorial de la Espiritualidad, 1957, pp. 2 y 8. 
Más allá de la inefabilidad de la expresión mística que se vierte en balbuceos y obliga al silencio, o a buscar símbolos de gran riqueza y densidad conceptual y amorosa (Bousoño, Mancho, Luce López-Baralt ${ }^{19}$ ), estos versos imbuidos de un simbolismo sugerente e inagotable, impregnados de tensión y misterio, todavía hoy enganchan al lector. Incluso se reescriben desde América: el puertorriqueño Darío Carrero, publicando en Trotta y recientemente fallecido, es un buen ejemplo. Hace unos años José Jiménez Lozano, uno de nuestros grandes escritores contemporáneos y Premio Nacional de las Letras, publicó El mudejarillo (1992), ${ }^{20}$ ficcionalización de la aventura de san Juan de la Cruz. En el apogeo del culto a la memoria, biografías y autobiografías inundan los escaparates de las librerías comerciales. ¿Cómo no recalar en la figura del pequeño fraile, amigo de Teresa y cofundador del Carmelo renovado junto a ella?

Siguiendo con la mística, el pasado centenario de Santa Teresa ha demostrado más allá de congresos y homenajes de eruditos de todos los pelajes, el atractivo que para el gran público tiene esta mujer cuya figura y escritura apasiona también a novelistas, ansiosos de ficcionalizarla en busca de su secreto:

“¡Pobre Teresa! Pasarán los años, correrán los siglos y la historia religiosa de la humanidad le concederá categoría máxima, no solo porque experimentó la presencia divina, sino porque además supo contarla como nadie antes la contó. Ella en su madurez mística explicará que fue merced de Dios saber entender qué es y saberlo decir." ${ }^{21}$

Son palabras de José María Javierre en su libro Teresa de Jesús, aventura humana y sagrada de una mujer (1978): como autor, dialoga con ella, la resucita para acosarla a preguntas desde una profunda empatía, como lo hará después en siglo XXI Rafael Gordon en su película Teresa, Teresa, sin tanta. No se trata solo de contar una historia peculiar (por cierto, muy bien contextualizada en la época española y universal del momento), sino de rescatar a la santa como modelo de mujer actual, a lo largo de 41 capítulos con un hilo conductor: ensalzar la vocación de las monjas de clausura:

“La madre Teresa traía monjas jovencillas (...) a rezar, amar y sufrir solas y apartadas, silenciosamente. Pero no las borraba del mundo, no las escondía, qué va. Ellas están ahí cumpliendo una tarea, su papel social. Monjas al servicio de la comunidad. Quiere que la gente alrededor lo sepa: alguien piensa y ama en nombre de todos".22

19 Cf. Luce López-Baratt, El sol a media noche.

20 Cf. José Jiménez Lozano, El mudejarillo, Barcelona, Anthropos, 1992.

21 Josemaría JavierRe, Teresa de Jesús. Aventura humana y sagrada de una mujer, Salamanca, Sígueme, 2001, 251. Otras publicaciones con ocasión del centenario podrían ser: Josefina Molina, En el umbral de la hoguera, Sevilla, Almuzara, 2015; Juan Manuel de PRADA, El castillo de diamante, Madrid, Espasa, 2015; o Espido Freire, Para vos nací, Barcelona, Ariel, 2015.

22 JAVIERRE, Teresa de Jesús, 9. 
El autor plantea un buen desafío a su lector, tan lejos hoy de esas coordenadas:"esa vocación es actual, hay una especial conexión entre la vida contemplativa y la dinámica evangelizadora" - le dice-. El libro es una biografía espiritual de la santa, su versión de la jugada divina y humana (Dios y ella) desde dentro... Muy controvertida en su tiempo, esa monja fundadora y andariega es hoy ensalzada por muchos. Ya el iv Centenario de su muerte (1982) provocó congresos y monografías (Vega-García Luengos, en el Centro virtual Cervantes le dedica una entrada muy completa a la santa ${ }^{23}$ ). Los críticos destacan su naturalidad narrativa:"escribió como vivió", forzó la lengua cotidiana y habló desde la experiencia. ¿Recepción actual? Mayorga en el teatro, Clara Sanchís en poesía, Josefina Molina y Gordon en cine, Espido Freire, Juan Manuel de Prada y la propia Molina en novela... entre otros.

Inevitable pasar por alto figuras y etapas en la relación cristianismo-literatura apasionantes en sí mismas y todavía hoy, como Newman y su labor en torno al Movimiento de Oxford; y las varias generaciones de conversos ingleses (Chesterton, Benson, Knox, Lewis, Tolkien...) tan bien estudiados por Pearce en su libro ${ }^{24}$. En esa metánoia que es literalmente la conversión de un ser humano, caben muchas posibilidades: las"tumbativas" a lo san Pablo, catalogables como"hechos extraordinarios" (Claudel, García Morente...): una experiencia oscura, pero la intuición se impone:"Dios existe, yo me lo encontré — dirá Frossard—. Las"racionales" (Chesterton, Lewis, Hahn), donde la honestidad del sujeto acaba aceptando la Verdad del Dios católico, no sin resistencias personales y de contexto. Porque el corazón gravita en torno a Cristo, pero las ideas no cambian como por arte de magia. En todos estos casos, el lector se encuentra ante el atestado de un "accidente" (la conversión con la que no se contaba), y genera un testimonio no contrastable: o lo tomas, o lo dejas. Porque el converso se enfrenta a lo que pasó (mejor, a lo que cree que pasó) y así lo cuenta. Ante la llamada perentoria de un Dios amoroso el hombre solo puede responder con su vida: negarle sería el infierno.

Imposible detenerse en cada uno de los fascinantes personajes del pasado siglo xx, cuyos escritos no han envejecido. Aun así, del bloque de conversos destaca un autor, Evelyn Waugh, y una novela llevada al cine (la serie de la BBC es una joya): Retorno a Brideshead (1945). El autor (1903-1966) es londinense, hijo de un conocido editor y crítico literario: buen lector, educado en Oxford y en el ambiente del espiritualismo finisecular del xIX propio de William James y los prerrafaelitas. Poco a poco, se convierte en un cínico anticlerical con cierto pesimismo pagano y tras una crisis personal y un matrimonio frustrado, inicia una búsqueda que culmina en su conversión religiosa del anglicanismo al catolicismo (1930), a través de un firme convencimiento intelectual, sin apoyo en

23 Cf. Germán Vega-García Luengos, Santa Teresa ante la crítica literaria del siglo XX, en el Centro virtual Cervantes, < http://www.cervantesvirtual.com/obra/santa-teresa-de-jesus-ante-la-critica-literaria-del-siglo-xx--0/> [consultado: 1 de junio de 2019].

24 Cf. Joseph PEARCE, Escritores conversos, Madrid, Palabra, 2006. 
emociones o gustos: "Yo reverencio a la Iglesia católica porque es verdad, no porque esté establecida o sea una institución. La fe es la esencia de la cosa misma" — dirá en varias ocasiones - Su conversión no cambia un carácter agresivo, tendente a rápidos cambios de humor, ni que sea un bebedor impenitente y un empedernido viajero, de cuya experiencia ha dejado su testimonio en multitud de libros de cuño autobiográfico.

Su producción de novelas es amplia (muchas traducidas en Anagrama), pero Retorno a Brideshead es especialmente interesante para hablar de cristianismo y literatura. ¿Por qué? El tema de fondo, apuntado por el narrador en su prefacio, es"la influencia de la gracia en un grupo de personajes muy diferentes entre sí, aunque estrechamente relacionados" ${ }^{25}$ Estamos ante una literatura de ideas, pero a la que interesa inspirar pensamientos a través de las actuaciones de los personajes, y no de un narrador explícito. Es el lector quien debe extraer las consecuencias de unas memorias escritas por el protagonista, militarizado durante la segunda guerra mundial. En su avance llegará a Brideshead, la mansión de sus íntimos amigos, y revivirá su juventud: en la primera parte, el encuentro con Sebastian en Oxford; en la segunda, las vacaciones en la mansión de su amigo, con la madre y sus hermanas Julia y Cordelia... las extrañas relaciones que entrecruzan sus vidas, la presencia del catolicismo como un dato escondido que marca la atormentada existencia de todos ellos, pendulando entre el placer evasionista y la virtud incomprendida. La ansiosa búsqueda de la felicidad los llevará a descubrirla en lo divino, no sin un arduo sufrimiento interior cuyo sentido pone de manifiesto Cordelia en la tercera parte:

"Me pregunto si te acuerdas de la historia que nos leyó mamá la primera noche que Sebastian se emborrachó...; quiero decir la noche mala. El padre Brown dijo algo así como le cogí (al ladrón) con un anzuelo y una caña invisibles, lo bastante largos como para dejarle caminar hasta el fin del mundo y hacerle regresar con un tirón del hilo". ${ }^{26}$

Homenaje a su gran amigo Chesterton: eso es lo que hace Dios con nosotros, como pretende demostrar esta novela, a través de diálogos antológicos (como "el apasionado coloquio de Julia sobre el pecado mortal o el soliloquio de lord Marchmain en su lecho de muerte"); o de pasajes teñidos de impresionismo pictórico y focalizaciones cinematográficas... fruto de una modernidad que todavía hoy tiene su garra.

Una última reflexión: cuando hablamos de cristianismo y literatura, ¿estamos hablando solo o preferentemente de escritores católicos? Los hubo y de primera: véase François Mauriac (1885-1970), premio Nobel de literatura criado entre las Landas y Burdeos, en una familia tradicional, católica y muy ligada a la tierra. Poeta, narrador, ensayista, dramaturgo... escribe textos en

25 Evelyn WAUGH, Retorno a Brideshead, Barcelona, Tusquets, 2008 (edición original 1945), 11.

26 WaUgH, Retorno a Brideshead, 262. 
gran medida autobiográficos cuyo tema son las grandes pasiones humanas. Se inscribe en la tradición de los grandes escritores realistas franceses como Stendhal, Flaubert, Balzac... cuyos personajes son grandes atormentados. La pregunta se impone: ¿escritor católico o un católico que escribe novelas? Se ha dicho de él que "no hay nada más lejos del tono edificante y moralizador que estos tumultuosos relatos interiores, que estas descripciones de los abismos pascalianos del alma sin la Gracia". Escuchemos sus palabras:

"Nudo de víboras (1932), novela católica, ilumina una verdad que durante toda mi vida he intentado demostrar e imbuir en ciertas mentes preclaras; y es el escándalo de esta monopolización del Cristo por los que no participan de su espíritu: este es, según mi parecer, el tema esencial de Nudo de víboras" ${ }^{27}$

Ante el lector se abre una confesión en primera persona en forma de carta escrita por Louis, (viejo avaro y solitario, necesitado de amor y comprensión), a su mujer Isa; una carta interrumpida por la muerte. Interesante el juego entre la historia del presente (viejo acosado por la familia para encerrarlo en un manicomio y desposeerle de la herencia), y el relato del narrador que en su carta recuerda toda su vida. Una novela de conversión y arrepentimiento, que refleja muy bien las inseguridades y los vaivenes de un alma ("Soy lo que soy... sería necesario convertirme en otro... ¡Oh Dios, Dios, si Tú existieras!”).

\section{2. ¿HA DESAPARECIDO DIOS DE LA LITERATURA?}

De entrada, habría que admitir que ya no se escriben novelas como las de E. Waugh o Mauriac. Hay quien dice que Dios ha desaparecido de nuestra literatura porque lo ha hecho en gran medida de nuestro mundo postmoderno. No es exactamente así: más bien quedaron atrás los siglos de Oro imbuidos de mística, o los existencialismos con la rebeldía y / o la búsqueda desgarrada de un Bernanos, Unamuno o los citados Waugh y Mauriac. Pero el ser humano, más despistado que nunca en un mundo al que podría aplicársele la metáfora de la Noche oscura del pequeño carmelita, sigue interesado por esos temas... ¿Ejemplos? Bestseller narrativos como Blanca como la nieve, roja como la sangre (2010), ${ }^{28}$ de Alessandro d'Avenia, llevada al cine en 2013; o El despertar de la señorita Prim (2013), ${ }^{29}$ de Natalia Sanmartin Fenollera, demuestran que se puede hacer una literatura asequible y de calidad, reescribiendo La vita Nuova de Dante, en el primer caso, o Newman y unos cuantos clásicos, en el segundo.Y todo ello manteniendo el slogan"a la ética por la estética”.

27 François Mauriac, Nudo de víboras, Madrid, Homo Legens, (edición oiriginal 1932), También en Obras Completas, 1953, 16.

28 Cf. Alessandro D'Avena, Blanca como la nieve, roja como la sangre, Barcelona, Grijalbo, 2010.

29 Cf. Natalia Sanmartin Fenollera, El despertar de la señorita Prim, Barcelona, Planeta, 2013. 
De hecho, un rastreo puntual y no exhaustivo dejaría algunos títulos interesantes en torno al fin de siglo donde, como sucedió a fines del XIX, conviven laicismo y fascinación por la figura humana de Cristo: El Evangelio según el hijo (1997), de Norman Mailer, novela en la que Cristo narra su aventura con fidelidad evangélica aunque con óptica muy humana, llena de dudas y humor; El Evangelio según van Hutten (1999), del argentino Abelardo Castillo, thriller sobre los orígenes esenios de las primeras comunidades cristianas, según él, escondidos por la Iglesia; La vida después de Dios (1997), ${ }^{30}$ de Douglas Coupland, conjunto de reflexiones, relatos o entradas de diario del protagonista. Mejor intencionada desde el punto de vista religioso que conseguida literariamente, y en el polo contrario por su apuesta por el catolicismo, Omega 666. El planeta gris (1996), del argentino Juan Luis Gallardo. Una distopía en la que se aceleran las disfunciones de nuestro mundo (contracepción, aborto, increencia...) hasta el punto de necesitar un nuevo comienzo, similar al de las primeras comunidades cristianas.

Otra cosa es La carretera (2006), una novela ganadora de un Pulitzer y escrita por el norteamericano McCarthy, visión apocalíptica y postmoderna de un padre y un hijo, caminantes hacia una dudosa salvación tras una debacle nuclear, cuestionándose todo. Como telón de fondo, la ausencia de Dios, la nostalgia del paraíso perdido... Desde otro ángulo y otro formato, el mismo McCarthy profundiza en el tema de Dios en El Sunset limited (2013), ${ }^{31}$ una batalla dialéctica sobre la condición humana entre un negro desharrapado y aun así creyente, y un profesor universitario triunfador, blanco aunque desesperanzado.

De calidad literaria, aunque heterodoxa en su planteamiento religioso de cara al cristianismo, Judas (2014), ${ }^{32}$ del judío Amos Oz, Premio Príncipe de Asturias varias veces propuesto al Nobel. Recoge viejos leitmotiv de la narrativa de $\mathrm{Oz}$, como el contexto de creación del estado de Israel que degeneró en la lucha entre judíos y palestinos, pero, más allá del problema sociopolítico, alude a la secular confrontación entre judíos y cristianos. Para estos últimos y según el escritor, todos los judíos son Judas, el traidor y según él verdadero fundador del cristianismo.Y la rivalidad entre ambos será eterna. Un texto no tan redondo como las memorias de Amos, Una historia de amor y oscuridad (2002), ${ }^{33}$ bestseller de ineludible lectura y donde se rozan alguna de estas cuestiones reiterativas en la narrativa de este autor pacifista recién fallecido.

En este panorama, destacan por su singularidad dos novelas La puerta de la misericordia (2002), ${ }^{34}$ del uruguayo Tomás de Mattos, una excelente visión del mundo cotidiano de los seguidores de Jesús, escrita con garra y fidelidad bíblica.

30 Cf. Douglas Coupland, La vida después de Dios, Barcelona, Ediciones B, 1997.

31 Cf. Cormac McCarthy, El Sunset limited, Madrid, Mondadori, 2013.

32 Cf. Amos Oz, Judas, Barcelona, De Bolsillo, 2017.

33 Cf. Amos Oz, Una historia de amor y oscuridad, Madrid, Siruela, 2004.

34 Cf. Tomás de Matros, La puerta de la misericordia, Madrid, Alfaguara, 2002. 
Una novela apasionante que recrea acontecimientos y personajes del relato evangélico en torno a Jesús, dejando abierta la puerta hacia el Absoluto a través de la misericordia divina. Una obra excepcional por su rareza y calidad literaria dentro del panorama de la literatura hispanoamericana contemporánea. Sin alcanzar ese nivel de compromiso ni situarse en el contexto histórico de la vida del Maestro, la novela El don de la fiebre (2018), ${ }^{35}$ del español Mario Cuenca Sandoval sitúa en el momento de la muerte a un compositor y organista católico, Olivier Messiaen (1908-1992) incidiendo en el sentido divino que para él tiene la música, su trabajo profesional.

Por su excepcionalidad, me detengo en una excelente novela que acaba de publicarse en España, premio de literatura católica francesa de 2018, La partitura interior (2019), ${ }^{36}$ de Reginald Gaillard. Profesor de secundaria, impulsor de al menos tres revistas y fundador de la editorial Corlevour, ha publicado tres poemarios y su condición de poeta es muy palmaria en La partition intérieure, su primera novela aclamada por la crítica francesa. Sorprende de entrada que el protagonista sea un anciano sacerdote que el Sábado Santo de 2012 rememora su vida en el pequeño pueblo de Revermont, "con la esperanza de que no desaparezca del todo de nuestras débiles memorias". ${ }^{37}$ Parisino, desterrado por su obispo del paraíso urbano, allí recaló en el 69 sin demasiado entusiasmo rozando los treinta años. Allí transcurrió su existencia y el medio transformó sus planteamientos haciéndole madurar en el contacto de los marginados: bien por su condición "especial" como en el caso de Charlotte, una mujer "retrasada" que vive en su mundo solitario en contacto con los muertos cuyas tumbas cuida en el cementerio; o bien por su condición atormentada, como el compositor parisino Jan, que se ha refugiado en la provincia para crear su obra y al que persigue el fracaso (en la línea deV. Woolf escribe obsesivamente cada día y lo rompe a continuación). La historia alternativa de estos dos personajes articula el texto y resume, en su excepcionalidad, las anécdotas de la vida pueblerina. El mensaje es claro: como en el Evangelio prostitutas y publicanos nos precederán en el reino de los cielos: "Solo la inocencia en Cristo permite el advenimiento de lo imposible" $:{ }^{38}$ algo que se aplica a Charlotte, mujer de la que el protagonista aprenderá casi todo. Las dicotomías habituales funcionan muy bien: frente a la urbe "civilizada", el campo aparentemente "dejado de la mano de Dios". Pero que tiene mucho que aportar a quien se aplique a ello con humildad: "Señor, (...) guía nuestros pasos, ayúdanos ahora que ya no estoy seguro de nada". ${ }^{39}$

35 Cf. Mario Cuenca Sandoval, El don de la fiebre, Barcelona, Seix, 2018.

36 Cf. Reginald GAILLARD, La partitura interior, Traducción y notas de José Antonio Millán Alb, Madrid, Encuentro, 2019 (Premio Literatura católica francesa 2018).

37 GAILLARD, La partitura interior, 132.

38 GAILLARD, La partitura interior, 131.

39 GAILLARD, La partitura interior, 105. 
Las dos primeras páginas sitúan las claves y dan al lector la textura de un relato reposado, denso, profundo, centrado en la exploración del interior de las personas, desde la óptica del protagonista. Estamos lejos de los sacerdotes de Bernanos o los personajes de Mauriac, en el desierto de una fe que se escapa o nunca se alcanzó. Aquí ese grito"Señor, Señor ¿por qué me has abandonado? ${ }^{40}$; "Señor, llevo en la cruz mi cólera y te grito a ciegas", ${ }^{41}$ arranque de un magnífico capítulo en cursivas bajo el título DIES IRAE situado en la recta final de la novela, se contrarresta con la rendida entrega de una libertad que a veces pesa al sacerdote:"Allí donde esté, te serviré. Si me has puesto aquí es porque juzgas que mi acción será aquí más útil que donde estaba hasta ahora". ${ }^{42}$ No en vano, se trata de un converso cuyas armas serán en adelante, silencio, escucha y oración. Porque"estar ahí y dar testimonio de Cristo es ya un acto de resistencia y de reconquista" ${ }^{43}$ Excelente mensaje para la dura tarea de los sacerdotes hoy.

Es obvio entonces que las primeras páginas también le dan al lector el punto de vista del relato, porque el destinatario explícito no es otro que el Señor, la Divina Providencia con la que se establece un diálogo continuo. En ese sentido, la novela es una confesión, un ajuste de cuentas al final de la vida en la línea de Nudo de víboras de Mauriac: un diálogo a tres bandas entre el protagonista, Dios y los demás. El primero va progresivamente despojándose de su yo para "desposarse" con los humildes (tantas veces violentos por exceso de dolor), los sepultados por el polvo de la historia que asume en su escritura como acompañó en su vida. Porque no en vano el sacerdote es Cristo en su vida terrena, e intercede ante el Altísimo:

“...esa obra anónima llevará la promesa de tu firma, Señor, el último día. Que ese día, una vez llegado, puedan no quedar desencantados, pues la mayor parte lo estuvieron a todo lo largo de su miserable vida. Han sufrido tanto y esperado tanto también. No los decepciones, te lo ruego... Que hayan sido cristianos o paganos, qué importa finalmente: no fueron tan malos, te digo, pese a sus faltas, pese a las palabras insensatas que no respondían a su pensamiento. He hecho lo que he podido para llevarlos a ti; acógelos pese a todo".$^{44}$

Dos tiempos (presente y pasado) en los trece capítulos sin numerar, precedidos de una introducción y culminados por un breve epílogo constituyen el flashback de toda una vida, la del sacerdote, condensada a través de cuidadas descripciones y sumarios narrativos, con un léxico cotidiano pero exquisito y una capacidad de sugerencia poética notable. Este punto de vista alterna con fragmentos del diario de Jan, "Algunas notas de fuego", que en dos ocasiones

40 GAILLARD, La partitura interior, 219.

41 GallLard, La partitura interior, 225.

42 Gaillard, La partitura interior, 27.

43 GaIlLARD, La partitura interior, 71.

44 GAILLARD, La partitura interior, 11-12. 
ofrece un contrapunto en su tortuosa búsqueda de la belleza. Su fracaso tiene que ver con "la historia de una mujer que atormentó su vida, quizá hasta destruirle lentamente e impedir que naciese su música". ${ }^{45}$ Las páginas de su diario ahondan en el misterio de la creación artística. La belleza es central, "solo lo bello hace más grande al hombre"46 — dirá Jan-; "embellecer la vida es dar gracias a Dios" ${ }^{47}$ — dirá el protagonista-.

En resumen, una novela que se imbrica en la tradición francesa, con una vuelta de tuerca muy personal, algo que vio muy bien su traductor, José Antonio Millán Alba, catedrático de la Universidad Complutense de Madrid, especialista en Baudelaire y la modernidad y traductor de Chateaubriand y otros, además de creador con su novela En penumbra (Encuentro, 2006). Que ha sabido detectar una novela imprescindible para el hombre de hoy que se angustia por muchas de las cuestiones que afloran aquí (el dolor, la libertad, el amor, la relación con lo divino...). No en vano, el autor es un converso del protestantismo, muy capaz por su trayectoria de asumir las miserias de los hombres con la misericordia, trasunto del amor divino. Y que con este libro tal vez ha puesto en práctica la petición de su protagonista: "concédenos gastar nuestra fe y las fuerzas que tenemos a imagen tuya en servicio de tu creación" ${ }^{48}$

Hablamos de novela en relación con Dios. Se diría que en un mundo desacralizado en el que parece no ser tema de moda, Dios se ha refugiado en dos reductos: la poesía y, sobre todo, el testimonio de conversos. ${ }^{49}$ Esta última es un auténtico boom en un momento en que las escrituras del yo (autobiografías, memorias, diarios...) están de moda como nuevo género literario. ¿Literatura o hagiografía? Dependerá de la calidad de los textos y el punto de vista del narrador, que va en primera persona como testigo insoslayable. Sea como fuere, si uno accede a Wikipedia, encontrará una inmensa lista ordenada alfabéticamente en la que pueden naufragar los ingenuos. En red se puede encontrar, igualmente, el proyecto Dios en la literatura contemporánea, un proyecto de investigación y de creación literaria, multidisciplinar e interuniversitario, liderado por el catedrático Antonio Barnés, que ya organizó dos congresos centrados en "Dios en los textos" y tiene anunciado un tercero para octubre del 2019, además de múltiples conferencias, mesas redondas... Como muestra un botón, la videoconferencia Cartografía literaria de Dios del 12 de diciembre del 2017. Mantiene también un blog.

Otra posibilidad online es acceder a la Via pulchritudinis, del Pontificio Consejo para la Cultura que también presenta un listado de obras y autores

45 GAILLARD, La partitura interior, 164.

46 GAILLARD, La partitura interior, 158.

47 GAILLARD, La partitura interior, 53.

48 GAILlaRd, La partitura interior, 227.

49 Cf. José Ramón Ayllón, Dios y los naúfrago, Barcelona, Bellacqua, 2002 y online; José Ramón Ayllón, 10 ateos cambian de autobús, Madrid, Palabra, 2009; Angelo Comastri, Quand le ciel s'ouvre: récits de conversions au XXe siécle, Nouan-le-Fuzelier, Eds. de Beatitudes, 2010; Jacinto PerAIRE, Conversos modernos, a micrófono abierto, Madrid, Ediciones de Buena Tinta, 2015. 
fundamentales para la literatura cristiana. Y siempre, como telón de fondo, la apasionante Carta de Juan Pablo II a los artistas. Porque Dios también puede buscarse en las artes contemporáneas, con dificultad en ocasiones; aun así, un reto que merece la pena.

Volviendo brevemente a los testimonios de conversos: en este sentido, resulta muy actual la aventura del matrimonio Hahn, presbiterianos de Estados Unidos, narrada en Roma dulce hogar. Nuestro camino al catolicismo (1993). Es un relato de conversión desde la doble óptica de marido y mujer. Scott la define como una historia de detectives, que degenera en relato de terror para llegar al final feliz: un romance con Cristo y su Iglesia. Arranca del rechazo de lo que consideran "errores católicos" (La Virgen, la infalibilidad del Papa...) para descubrir que:

"para mi desconcierto y frustración, la Iglesia católica romana, a la que yo combatía, empezaba a aportar las respuestas correctas, una tras otra. Después de algunos casos más, la cosa empezó a resultar escalofriante".$^{50}$

El matrimonio, apostólico a tope, formado paralelamente en un seminario, se tambalea. El relato del drama tiene momentos divertidos: ante lo irremediable de la conversión debida a la coherencia doctrinal de Scott, Kimberly va proponiendo lo que considera menos malo: “¿no podríamos hacernos episcopalianos?". ${ }^{51}$ Hasta que, pasado el tiempo, confiesa a su marido: "Dios me está llamando a entrar en la Iglesia católica". Las consecuencias a corto plazo son duras (pérdida de trabajo, de amigos, de seguridades...). En una época desgraciadamente cuajada de persecuciones a los católicos por todo el planeta (y aquí podrían citarse libros sobrecogedores), el testimonio de un matrimonio comprometido hasta la médula te agarra y te cuestiona: ¿cómo vivo mi fe y mi relación con Jesucristo?

Con ojos nuevos ${ }^{52}$ es un relato muy distinto de una mujer joven de la nobleza romana, Alessandra Borghese, laica y frívola que, en un determinado momento y por medio de una amiga, reencuentra la fe en la que se educó. "Durante largos años he buscado respuestas tirándome de cabeza a la vida" — dirá en el prólogo- porque "pertenecer a una clase privilegiada, poseer medios, ser de estirpe aristocrática, tener cultura y alcanzar éxitos profesionales puede parecer decisivo, pero... en absoluto es así, si no tienes ese sutil rayo de Luz que te indica el camino". La angustia reinaba en el corazón de quien alimentaba prejuicios contra la fe cristiana, era en verdad frágil y estaba sustancialmente sola, como todos los que excluyen a Dios de su vida. Lo descubrirá paulatinamente, en un camino hacia la paz y la alegría, el camino de la conversión que ocupa el

50 Scott y Kimberly HAHN, Roma dulce hogar. Nuestro camino al catolicismo, Madrid, Rialp, 2014, 62.

51 HaHn, Roma dulce hogar, 76.

52 Cf. Alerssandra Borghese, Con ojos nuevos. Un viaje a la fe, Madrid, Rialp, 2006. 
prólogo, con referencias a la también conversión del editor Mondadori, amigo de Messori, otro converso... Después, en un flashback, vuelve atrás para narrar su vida que culmina en ese momento en que"experimenté un enorme consuelo, sentí que renacía. Descubrí, con una alegría que ni de lejos consigo describir, que Dios estaba allí para mí, para acogerme y ofrecerme su ayuda". Lo demás será consecuencia de ese descubrimiento.

Conversos europeos o, al menos, de ascendiente cristiano. La bibliografía al respecto es amplísima, también como bibliografía secundaria, es decir, los estudios sobre el tema. Cito solo uno recién salido del horno: Conversos buscadores de Dios. 12 historias de fe de los siglos XX y XXI (2019), de Pablo J. Ginés, ${ }^{53}$ que condensa en breves páginas la conversión de personajes super mediáticos del siglo XX, arrancando con Gary Cooper.

Otro mundo es el de los conversos de otras religiones, especialmente del Islam. Elijo dos: Defendiendo a Alá llegué a Jesús. Las razones de mi conversión (2017), de Nabel Qureshi ${ }^{54}$ es el relato de un paquistaní emigrado con su familia a Estados Unidos, un islamista convencido y devoto que poco a poco descubrirá la alternativa del cristianismo. El precio a pagar ((2017), de Joseph Fadelle ${ }^{55}$ es el corto pero aterrador relato de un iraquí, musulmán convencido que, de manera tumbativa descubre al Señor al confrontar el Corán con los Evangelios. ¿El resultado? La intransigencia familiar y la sharia o ley islámica que condena a muerte al converso y a quienes le reciban, en este caso, los cristianos que viven su religión casi en las catacumbas. La espectacular y complejísima huida a Francia convive con la amargura del converso, a quien cuesta perdonar la condena a muerte dictada contra él por su propia familia de sangre. En ambos destaca la honradez de la búsqueda y la solidez de una fe recién adquirida que los lleva a enfrentarse a lo más querido y al exilio.

En conclusión: Dios sigue interesando y eso se plasma en la literatura: lo pone de manifiesto un bestseller narrativo, la novela Sumisión (2015), de Michel Houellebecq ${ }^{56}$ traducida por Anagrama. Es una mirada ¿profética? a una Francia convertida totalmente al Islam que se ha impuesto incluso en las esferas del poder. ¿Qué pasaría si esto llegara a ser una realidad? Bajo la forma del diario de un profesor universitario descubrimos que una sociedad descristianizada y sin valores como la nueva puede, a corto plazo, caer sin resistencia en las redes de una religión mucho más fanática y capaz de ofrecer la vida por sus ideas.

La literatura sobre Dios interesa: ¿otro ejemplo que viene de Francia? El inusitado éxito de Fabrice Hadjadj, converso del Islam él mismo, en libros

53 Cf. Pablo GINÉs, Conversos buscadores de Dios. 12 historias de fe de los siglos XX y XXI, Madrid, Digital Reasons, 2019.

54 Cf. Nabeel QuReshi, Defendiendo a Alá llegué a Jesús. Las razones de mi conversión, Barcelona, Ciudadela, 2017.

55 Cf. Joseph FADELLE, El precio a pagar, Madrid, Rialp, 2017.

56 Cf. Michel Houllebece, Sumisión, Barcelona, Anagrama, 2015. 
como La fe de los demonios (2014) ${ }^{57}$ o Tenga Ud. éxito en su muerte (Anti método para vivir) (2011 ${ }^{58}$ redactados con altura apologética, junto al desenfado de quien vive según esa ya vieja fórmula de 1928 refrendada por elVaticano II: "ser contemplativos en medio del mundo". Últimas noticias del hombre (y de la mujer), ${ }^{59}$ traducido por Enrique García-Máiquez para la editorial Homo Legens (2018) es, por ahora su última entrega.

¿Un ejemplo todavía más cercano? ¿Alguien entiende a Dios? ${ }^{60}$ Escrito por Javier Hernández Pacheco en 2014, son "reflexiones sobre el Catecismo de un catedrático de filosofía, un catedrático de universidad que no ha olvidado un axioma fundamental:" ique no sucumba la Estética ante una Ética malentendida!”. Por eso su ensayo está fantásticamente bien escrito, es ágil e inteligente, teñido de sano humor. Mucho más interesante que el último bestseller de Harari.

Porque somos laicos y el "quedeme y olvideme" propio de los cartujos es un milagro que solo consiguen unos pocos privilegiados. Aun así, no deja de ser paradójico que todavía hoy se proponga conectar con la Palabra desde el silencio (cfr. el último libro del Cardenal Sarah, La fuerza del silencio. Frente a la dictadura del ruido (2017) ${ }^{61}$, o el documental sobre la Gran Cartuja). Por cierto, es apasionante la aventura del cardenal Sarah entrevistado en Dios o nada (2015), ${ }^{62}$ o de cómo un desharrapadillo analfabeto de un poblado africano llega a Prefecto de la Congregación para el Culto Divino.

No deja de ser paradójico también que se elija a las comunidades benedictinas de la Edad Media como paradigma de lo que debería ser la educación de la familia en el mundo actual, un reducto que insufle la fe a nuestros jóvenes en un momento histórico aparentemente sin valores. Me refiero a La opción benedictina. Una estrategia para los cristianos en una sociedad poscristiana (2018), ${ }^{63}$ que nos llega de Estados Unidos de la mano de Rod Dreher. Ejemplos todos ellos de que la literatura, en el sentido amplio del término, en absoluto constreñido a la novela como en épocas anteriores, sigue abriéndose paso y siendo fecundada por el cristianismo tras 2000 años de civilización occidental.

57 Cf. Fabrice Hadjadj, La fe de los demonios (o el ateísmo superado), Granada, Nuevo Inicio, 2014.

58 Cf. Fabrice HADJADJ, Últimas noticias del hombre (y de la mujer), Madrid, Homo Legens, 2018.

59 Cf. Fabrice Hadjadj, Tenga usted éxito en su muerte. Antimétodo para vivir, Granada, Nuevo Inicio, 2011.

60 Cf. Javier Hernández PACHeCO, ¿Alguien entiende a Dios? Reflexiones sobre el catecismo de un profesor de filosofía, Madrid, Sekotia, 2014.

61 Cf. Robert SARAH, La fuerza del silencio. Frente a la dictadura del miedo, Madrid, Palabra, 2017 (con Nicolas Diat).

62 Cf. Ronald SARaH, Dios o nada. Entrevista sobre la fe, Madrid, Palabra, 2015 (con Nicolas Diat).

63 Cf. Rod DREHER, La opción benedictina. Una estrategia para los cristianos en una sociedad poscristiana, Madrid, Encuentro, 2018. 